\title{
Antithrombotic treatment following transcatheter valve replacement: current considerations
}

\author{
Ioanna Koniari ${ }^{1}$, Nicholas G. Kounis ${ }^{2}$, George Hahalis ${ }^{2}$ \\ ${ }^{1}$ Department of Cardiology, Royal Bromptom Hospital, London, England; ${ }^{2}$ Department of Cardiology, University of Patras Medical School, Rion, \\ Patras, Achaia, Greece \\ Correspondence to: Nicholas G. Kounis, MD, PhD. Department of Cardiology, University of Patras Medical School, Queen Olgas Square, 7 Aratou \\ Street, Patras, Achaia, Greece. Email: ngkounis@otenet.gr. \\ Provenance: This is an invited Editorial commissioned by the Section Editor Hai-Long Dai (Department of Cardiology, Yan'an Affiliated Hospital of \\ Kunming Medical University, Kunming, China). \\ Comment on: Rodés-Cabau J, Masson JB, Welsh RC, et al. Aspirin Versus Aspirin Plus Clopidogrel as Antithrombotic Treatment Following \\ Transcatheter Aortic Valve Replacement With a Balloon-Expandable Valve: The ARTE (Aspirin Versus Aspirin + Clopidogrel Following \\ Transcatheter Aortic Valve Implantation) Randomized Clinical Trial. JACC Cardiovasc Interv 2017;10:1357-65.
}

Submitted Sep 28, 2017. Accepted for publication Oct 01, 2017.

doi: $10.21037 /$ jtd.2017.10.34

View this article at: http://dx.doi.org/10.21037/jtd.2017.10.34

Transcatheter aortic valve implantation (TAVI) or transcatheter aortic valve replacement (TAVR) has been established as a vital alternative to surgical aortic valve replacement (AVR) for intermediate and high surgical risk patients. TAVR has been demonstrated to be either non inferior or even superior to AVR regarding annual all-cause mortality in high risk operable patients, with the implantation of Edwards Sapien valve (ESV) and in Medtronic CoreValve Revalving System (CRS) respectively $(1,2)$. Also, TAVR has been proven superior to optimal medical treatment concerning 1 year all-cause mortality in patients with severe aortic stenosis who cannot undergo surgery (3). Despite the advanced age, comorbidities and fragile status of patients undergoing TAVR, the procedure is currently correlated with a high success rate. However, major ischemic and bleeding events can further complicate the procedure, impairing survival. Therefore, the recommendation of the most appropriate antithrombotic treatment in this high-risk population balancing the risk/ benefit ratio is rendered of major clinical importance.

Four large randomized clinical trials PARTNER A and B $(1,3)$, CUSPT (2) and CHOICE (4) with comparable baseline characteristics but higher mean logistic EuroSCORE, STS score and previous stroke incidence in PARTNER trials (Table 1), constitute the cornerstone studies reflecting ischemic and bleeding complications under dual antiplatelet therapy (DAPT) for the first 3-6 months and single indefinitely. Placement of Aortic Transcatheter Valves (PARTNER) trial A and B compared TAVI to surgical AVR and medical treatment respectively, administrating 75-100 $\mathrm{mg}$ aspirin indefinitely and combined with clopidogrel for the first 6 months.

The Medtronic CoreValve U. S. Pivotal Trial (CUSPT) and The Comparison of Transcatheter Heart Valves in High Risk Patients With Severe Aortic Stenosis: Medtronic CoreValve $v s$. Edwards SAPIEN XT (CHOICE) trial compared TAVI versus SAVR and a balloon versus selfexpandable TAVI respectively, recommending low to normal dose aspirin indefinitely (81-325 or $100 \mathrm{mg}$ ) and clopidogrel for 3 months $(2,4)$. As described in Table 1 , 30 -day all-cause mortality rates were comparable ranging from $3.3 \%$ to $5.1 \%$, while 1 -year all-cause mortality was increased to PARTNER trials compared to CUSPT (24.2\% and $30.7 \%$ versus $14.2 \%$ respectively). Thromboembolic events as myocardial infarction and stroke at 30 days demonstrated no significant differences varying between $0-0.8 \%$ and $2.6-6.7 \%$, respectively, whereas 30 -day major vascular access related complications were significant decreased in CUSPT compared to PARTNER A, B and CHOICE trials $(5.9 \%$ versus $11 \%, 16.2 \%$ and $12.8-14 \%$, respectively). However, major bleeding rates at 30 days presented an increase in CUSPT compared to PARTNER 
Table 1 Randomized clinical trials referring to antiplatelet therapy pre- and post-TAVI and respective outcomes

\begin{tabular}{|c|c|c|c|c|}
\hline Randomized clinical trials & PARTNER A (1) & PARTNER B (3) & CUSPT (2) & CHOICE (4) \\
\hline Sample size & 348 & 179 & 394 & $221\left(238^{\star}\right)$ \\
\hline Age (years) & $83.6 \pm 6.8$ & $83.1 \pm 8.6$ & $83.2 \pm 7.1$ & 80.75 \\
\hline Male (\%) & 57.8 & 45.8 & 53.6 & 35.65 \\
\hline STS score & $11.8 \pm 3.3$ & $11.2 \pm 5.8$ & $7.3 \pm 3.0$ (STS-PROM) & 5.9 \\
\hline NYHA III/IV (\%) & 94.3 & 92.2 & 85.8 & $61 / 19.9$ \\
\hline Coronary artery disease (\%) & 74.9 & 67.6 & 75.4 & 63.05 \\
\hline Cerebral vascular disease (\%) & 29.3 & 27.4 & 12.9 & 19.9 \\
\hline Pulmonary hypertension (\%) & 42.4 & 42.4 & NA & NA \\
\hline $\operatorname{AVA}\left(\mathrm{cm}^{2}\right)$ & $0.7 \pm 0.2$ & $0.6 \pm 0.2$ & $0.72 \pm 0.23$ & 0.7 \\
\hline Mean aortic valve gradient $(\mathrm{mmHg})$ & $42.7 \pm 14.6$ & $44.5 \pm 15.7$ & $48.27 \pm 15.31$ & 43.15 \\
\hline Moderate/severe MR (\%) & 19.8 & 22.2 & NA & 36.15 \\
\hline \multicolumn{5}{|l|}{ Antiplatelet therapy pre TAVI } \\
\hline Aspirin (mg) & $75-100$ & $75-100$ & $81-325$ & 100 \\
\hline Clopidogrel (mg) & 300 & 300 & 300 & NA \\
\hline \multicolumn{5}{|l|}{ Antiplatelet post TAVI } \\
\hline ESV: Edwards Sapien valve (\%) & 100 & 100 & 0 & 50 \\
\hline \multicolumn{5}{|l|}{ Outcomes: 30-day and 1-year } \\
\hline 30-day all-cause mortality (\%) & 3.4 & 5 & 3.3 & $4.1^{\$} / 5.1^{\&}$ \\
\hline 30-day cardiovascular mortality (\%) & 3.2 & 4.5 & 3.1 & $4.1^{\$} / 4.3^{\&}$ \\
\hline 1-year all-cause mortality (\%) & 24.2 & 30.7 & 14.2 & NA \\
\hline 1-year cardiovascular mortality (\%) & 14.3 & 19.6 & 10.4 & NA \\
\hline Myocardial infarction at 30 days (\%) & 0 & 0 & 0.8 & $0.8^{\$} / 0^{\&}$ \\
\hline Myocardial infarction at 1 year (\%) & 0.4 & 0.6 & 1.9 & NA \\
\hline Stroke at 30 days (\%) & 4.7 & 6.7 & 4.9 & $5.8^{\$} / 2.6^{\&}$ \\
\hline Stroke at 1 year $(\%)$ & 6 & 10 & 8.8 & NA \\
\hline
\end{tabular}

Table 1 (continued) 
Table 1 (continued)

\begin{tabular}{|c|c|c|c|c|}
\hline Randomized clinical trials & PARTNER A (1) & PARTNER B (3) & CUSPT (2) & CHOICE (4) \\
\hline $\begin{array}{l}\text { Major vascular access site related complication at } \\
30 \text { days }(\%)\end{array}$ & 11 & 16.2 & 5.9 & $14^{\$} / 12.8^{\&}$ \\
\hline Major bleeding at 1 year (\%) & 14.7 & 22.3 & 29.5 & NA \\
\hline Life threatening bleeding at 30 days (\%) & NA & NA & 13.6 & $8.3^{\$} / 12^{\&}$ \\
\hline New onset $A F$ at 30 days (\%) & 8.6 & 0.6 & $11.7^{\# \#}$ & NA \\
\hline New onset $A F$ at 1 year (\%) & 12.1 & 0.6 & $15.9^{\# \#}$ & NA \\
\hline New pacemaker implantation at 30 days (\%) & 3.8 & 3.4 & 19.8 & $17.3^{\$} / 37.6^{8}$ \\
\hline
\end{tabular}

A, B and CHOICE trials $(28.1 \%$ versus $9.3 \%, 16.8 \%$ and $14.5-19 \%)$.

There are also six VARC reporting registries with a great variance in sample size, baseline characteristics, mean logistic EuroSCORE, previous stroke and coronary artery disease history, as described in Table 2 (5-10). Regarding the antiplatelet therapy, low dose aspirin 75-100 mg recommended indefinitely, while clopidogrel duration varied mainly between 1 and 6 months. In these registries, all-cause mortality at 30 days reported between a range of $2.1-16 \%$ and stroke incidence between $1-6 \%$. Transfemoral access is reported in the majority of procedures presenting a variance in major vascular access site related complications (VASC) at 30 days between $2.9-10.7 \%$. In addition, major bleeding rates at 30 days revealed significant differences (1-20.9\%).

Notably, additional five studies have compared directly the ischemic and bleeding endpoints of single versus DAPT post TAVI. The rationale of DAPT in TAVI patients consists in the ischemic event prevention, especially stroke, periprocedurally as well as in the first month post the procedure. The ARTE, SAT-TAVI and Ussia et al. randomized trials demonstrated the lack of any beneficial impact of DAPT (aspirin and clopidogrel) on the stroke prevention post TAVR (11-13). Interestingly, ARTE trial (11) randomized 222 patients to aspirin versus aspirin plus clopidogrel following TAVR and revealed no significant difference in the 30 - and 90 -day stroke rate $(0.9 \%$ versus
$2.7 \%$ in aspirin versus DAPT groups), except a general tendency toward a lower incidence of mortality, myocardial infarction and stroke of aspirin alone, as described in Table 3. Similarly, SAT-TAVI trial (12) randomized 120 patients undergoing TAVR to aspirin versus aspirin and clopidogrel and showed no difference in 30-day major stroke rate (1.7\% in both groups). Ussia et al. (13) reported a 30-day stroke rate of $5 \%$ in aspirin versus 3\% in DAPT group, in a total population of 79 patients following TAVR with the CoreValve system. In accordance with these results, two recent meta-analyses reported similar cerebrovascular event rates in TAVR patients receiving aspirin versus DAPT $(16,17)$. Overall, SAT-TAVI (12) and Ussia et al. (13) trials, presented no significant differences in both 30-day ischemic (mortality, myocardial infarction, stroke) and bleeding events between aspirin monotherapy and DAPT, except the lower rate of cumulative major and minor VASC complications in aspirin versus DAPT treated patients (5\% versus $13.3 \%$, $\mathrm{P}<0.05)$ in the SAT-TAVI trial.

Durand et al. (14) compared prospectively two antiplatelet therapy strategies, using single (aspirin or clopidogrel) versus DAPT (aspirin and clopidogrel) in 362 consecutive patients that enrolled in the FRANCE 2 TAVI registry. Similar to the previous mentioned studies (11-13), the mortality and thromboembolic event rates demonstrated no difference between single and dual antiplatelet treated groups. In accordance with SAT-TAVI trial, overall vascular complications were significantly reduced in single 
Table 2 Registries referring to antiplatelet therapy post TAVI and the corresponding outcomes

\begin{tabular}{|c|c|c|c|c|c|c|}
\hline Registries & $\begin{array}{l}\text { Gilard } \\
\text { et al. (5) }\end{array}$ & $\begin{array}{l}\text { Nuis } \\
\text { et al. (6) }\end{array}$ & $\begin{array}{l}\text { Tchetche et al. } \\
\text { (7) }\end{array}$ & $\begin{array}{l}\text { Borz et al. } \\
\quad(8)\end{array}$ & $\begin{array}{l}\text { Griese } \\
\text { et al. (9) }\end{array}$ & $\begin{array}{l}\text { Abramowitz } \\
\text { et al. (10) }\end{array}$ \\
\hline \multicolumn{7}{|l|}{ Characteristics } \\
\hline Age (years) & $82.7 \pm 7.2$ & $80 \pm 8$ & $81 \pm 7$ & $83.3 \pm 6.5$ & $82 \pm 5$ & $83 \pm 5$ \\
\hline Male (\%) & 51 & 50 & 53.8 & 46 & 29.6 & 39 \\
\hline STS score (\%) & $14.4 \pm 11.9$ & $3.4-7.5$ & NA & NA & NA & NA \\
\hline NYHA III/IV (\%) & 75.9 & 82 & 81.1 & NA & 81.5 & NA \\
\hline Coronary artery disease (\%) & 47.9 & $24^{y}$ & 45.1 & 34.8 & $9.9^{9}$ & 57 \\
\hline Cerebral vascular disease (\%) & 10 & 23 & 15.7 & NA & 8 & 8.4 \\
\hline Pulmonary hypertension (\%) & 19.6 & NA & NA & NA & NA & NA \\
\hline CRS: Medtronic CoreValve Revalving System (\%) & 33.1 & 100 & NA & 0 & 18.5 & NA \\
\hline ESV: Edwards Sapien valve (\%) & 66.9 & 0 & NA & $\begin{array}{l}50.8 ; 49.2 \\
\text { XT Sapien }\end{array}$ & $\begin{array}{l}81.5 \times \mathrm{XT} \\
\text { Sapien }\end{array}$ & NA \\
\hline Transfemoral access (\%) & 74.6 & 95 & $\begin{array}{l}84(9.1 \\
\text { surgical) }\end{array}$ & 76 & 100 & NA \\
\hline Transapical/other (\%) & $17.8 / 7.6$ & $0 / 5^{j}$ & $9.4 / 6$ & 24 & 0 & NA \\
\hline \multicolumn{7}{|l|}{ Antiplatelet therapy pre-TAVI } \\
\hline Aspirin (mg) & $\leq 160$ & 80 & NA & 250 IV & 100 & NA \\
\hline \multicolumn{7}{|l|}{ Outcomes at 30 days and 1 year* } \\
\hline All-cause mortality 30 days (\%) & $9.7 ;\left(24^{\star}\right)$ & $16^{\mathrm{k}} / 6^{\mathrm{m}}$ & 7.2 & 7.6 & 5.6 & $a=2.1 ; b=2.9$ \\
\hline Cardiovascular mortality 30 days (\%) & $7 ;\left(14.3^{\star}\right)$ & NA & 6.3 & NA & NA & NA \\
\hline Myocardial infarction at 30 days (\%) & $N A ;\left(1.2^{*}\right)$ & NA & 1.59 & 2 & NA & 0 \\
\hline Stroke 30 days (\%) & $3.4 ;\left(4.1^{\star}\right)$ & 6 & 2.6 & 2.4 & NA & $a=2.8 ; b=1$ \\
\hline $\begin{array}{l}\text { Major vascular access site related complication } \\
30 \text { days }(\%)\end{array}$ & $\mathrm{NA} ;\left(4.7^{*}\right)$ & NA & 10.7 & 6.4 & 4.3 & $a=3.5 ; b=2.9$ \\
\hline Major bleeding 30 days (\%) & $\mathrm{NA} ;\left(4.5^{\star}\right)$ & NA & 20.9 & 9.6 & 3.7 & $a=2.1 ; b=1$ \\
\hline Life threatening bleeding 30 days (\%) & $\mathrm{NA} ;\left(1.2^{*}\right)$ & NA & 13.9 & 13.2 & 9.9 & NA \\
\hline New onset AF at 30 days (\%) & NA & NA & NA & NA & NA & NA \\
\hline New pacemaker implantation 30 days (\%) & $\begin{array}{l}\mathrm{NA} ; \\
\left(15.6^{\star}\right)\end{array}$ & NA & 15.5 & 6.1 & NA & $\begin{array}{l}a=24.3 \\
b=22.9\end{array}$ \\
\hline
\end{tabular}

\footnotetext{
*, 1 year outcome only available in Gilard et al. study; ${ }^{y}$, previous MI; ${ }^{k}$, patients with stroke; ${ }^{m}$, patients without stroke; ${ }^{\text {, }}$, surgical access; ${ }^{g}$, previous MI; a, group 1 with aortic stenosis and coronary artery disease; b, group 2 with aortic stenosis. NA, not available; TAVI, transcatheter aortic valve implantation; ESV, Edwards Sapien valve; IV, intravenous.
} 


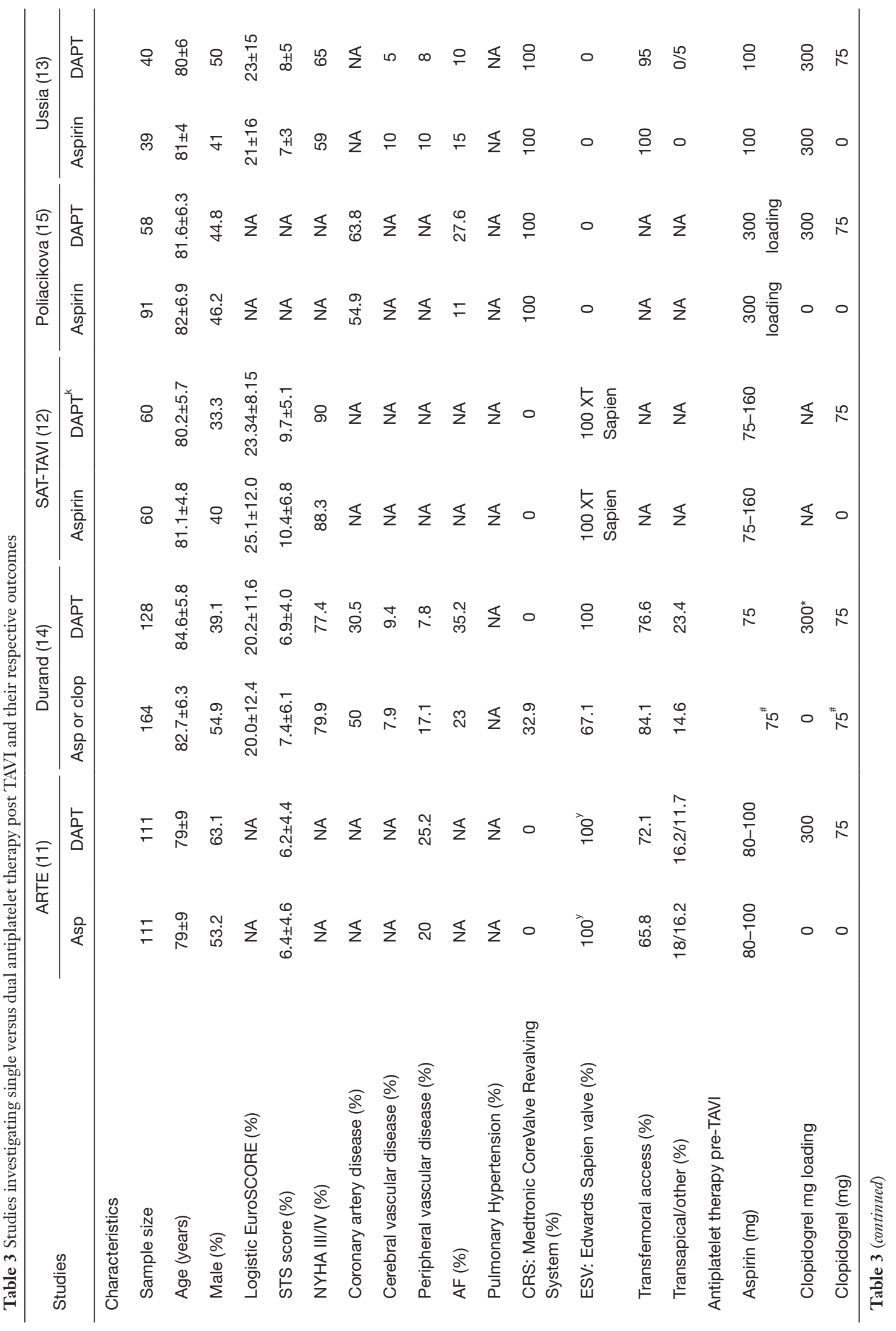




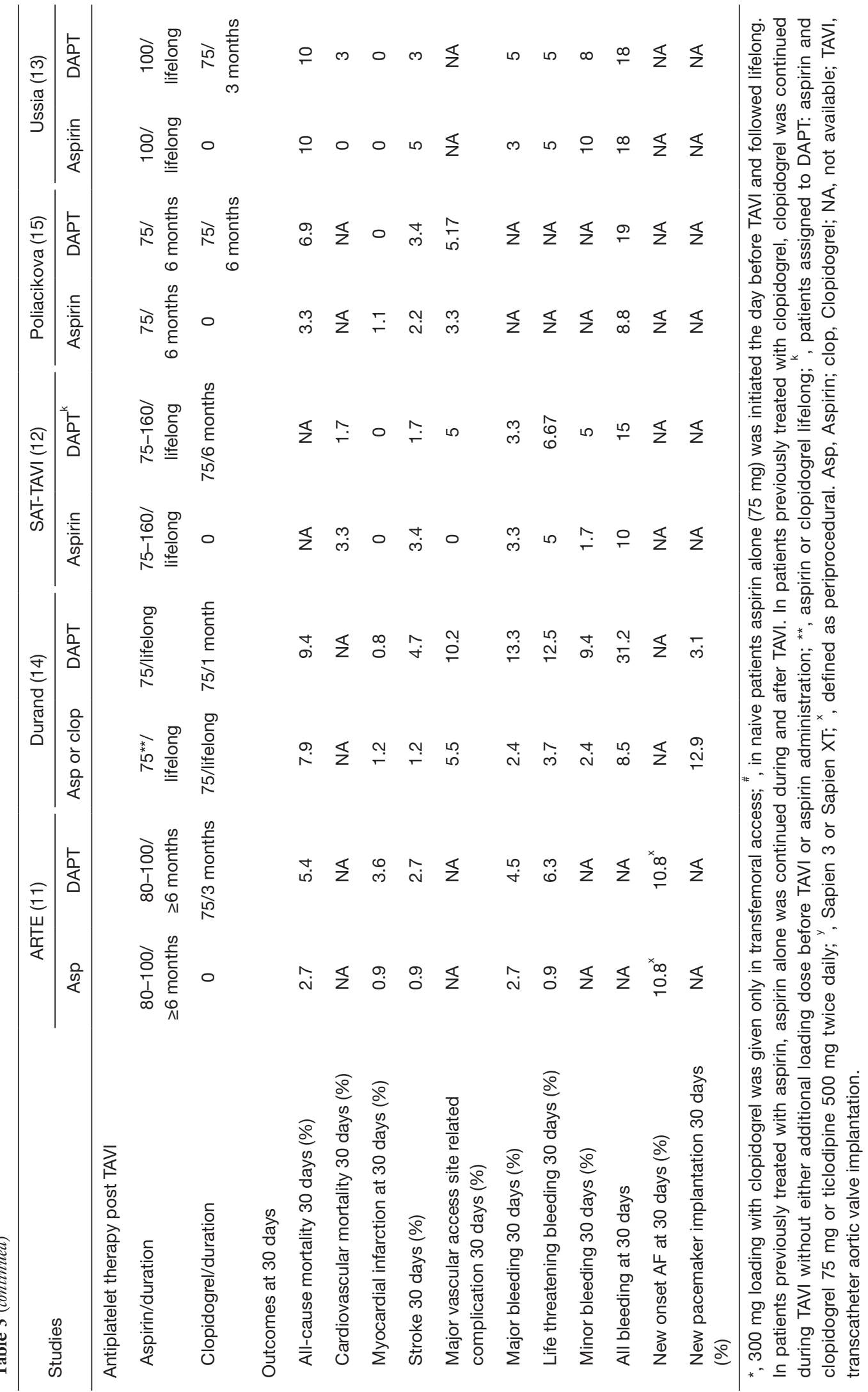


antiplatelet therapy $(7.9 \%$ versus $19.5 \%, \mathrm{P}=0.003)$. DAPT treated patients presented a significant increase in minor VASC compared to single aspirin or clopidogrel therapy (9.4\% versus $2.4 \%, \mathrm{P}=0.017$ ) and an increased but nonsignificant frequency in major VASC $(10.2 \%$ versus $5.5 \%, \mathrm{P}=0.134)$, respectively. All bleeding, major and lifethreatening bleeding, as well as the transfusion rates were significantly elevated in the DAPT versus single antiplatelet therapy $(31.2 \%$ versus $8.5 \%, \mathrm{P}<0.0001 ; 13.3 \%$ versus $2.4 \%, \mathrm{P}<0.0001 ; 12.5 \%$ versus $3.7 \%, \mathrm{P}=0.005 ; 25 \%$ versus $7.3 \%, \mathrm{P}<0.0001$; respectively). Also, Poliacikova et al. (15) retrospective study demonstrated an trend towards increased 30-day bleeding rates in DAPT versus aspirin treated patients, not reaching statistical significance $(\mathrm{P}=0.069$ for both in-hospital and 30-day bleeding). The composite of all-cause mortality, acute coronary event, stroke, and all bleeding was significantly increased in DAPT versus aspirin group (in-hospital $\mathrm{P}=0.01$ and 30 -day follow up $\mathrm{P}=0.02$ ), difference driven mainly by bleeding complications as major adverse cardiac and cerebrovascular event rates were similar in two groups. Similarly, ARTE trial revealed that aspirin reduced significantly the risk of composite major and life threatening bleeding compared to DAPT in TAVR patients (3.6\% versus $10.8 \%, P=0.038$ ), without increasing the risk of stroke or myocardial infarction (11). Indeed, ARTE trial confirmed that DAPT is correlated with an increased rate risk of severe bleeding [major or life threatening compared to patients receiving aspirin (11)]. Notably, the majority of bleeding events in DAPT treated patients were correlated with vascular access site complications, whereas a great number of non-access related bleedings such as gastrointestinal bleeding recorded in these patients. In addition, the majority of life threatening bleeding events (88\%) were observed in DAPT treated patients, fact that further supports the higher incidence and severity of bleeding complications during dual antiplatelet treatment in consistence with other studies $(18,19)$.

The POPULAR-TAVI (Antiplatelet Therapy for Patients Undergoing Transcatheter Aortic Valve Implantation) trial (NCT02247128) is expected to elucidate the impact of aspirin versus DAPT on bleeding events as a single primary outcome in TAVR patients.

Interestingly, bleeding events have been proven to outweigh significantly cerebrovascular events, as major bleedings are correlated with worse outcomes and even increased mortality post TAVR procedures (20-22). Bleeding complications could be attributed to both of the great invasive nature of TAVR as well as the high risk profile and fragility of elderly patients undergoing the procedure. Given these parameters, it is inevitable that DAPT will be related with increased bleeding risk. On the other hand, no beneficial impact of DAPT over single antiplatelet therapy regarding cerebrovascular event prevention has been proven by several TAVR studies (23-26). It is well known that $50 \%$ of strokes within the first month post TAVR occur periprocedurally or within 24 hours post procedure, whereas the stroke risk seems to peak within the first 7 days post TAVR (11). Acute strokes stem from embolic events during the mechanical interaction of the transcatheter valve system with the highly calcified native aortic valve, while subacute strokes can be induced by more traditional predisposing factors such as atrial fibrillation. Neither periprocedural embolization nor atrial fibrillation could be prevented by DAPT, rendering further the limited therapeutic potential of DAPT.

Consequently, it is evident that DAPT increases significantly bleeding complications without reducing ischemic events post TAVR. In conclusion, major advances have been accomplished in the field of TAVI. However, ischemic and bleeding complications remain prevalent impairing survival in TAVR patients. Small randomized studies and meta-analyses have demonstrated a lack of benefit of DAPT over single antiplatelet therapy, as DAPT is correlated with increased bleeding events without decreasing thromboembolic complications post TAVR. Further, large scale studies should be performed to elucidate the optimal antithrombotic treatment post TAVR.

\section{Acknowledgements}

None.

\section{Footnote}

Conflicts of Interest: The authors have no conflicts of interest to declare.

\section{References}

1. Smith CR, Leon MB, Mack MJ, et al. Transcatheter versus surgical aortic-valve replacement in high-risk patients. $\mathrm{N}$ Engl J Med 2011;364:2187-98.

2. Adams DH, Popma JJ, Reardon MJ, et al. Transcatheter aortic-valve replacement with a self-expanding prosthesis. N Engl J Med 2014;370:1790-8.

3. Leon MB, Smith CR, Mack M, et al. Transcatheter aortic- 
valve implantation for aortic stenosis in patients who cannot undergo surgery. N Engl J Med 2010;363:1597-607.

4. Abdel-Wahab M, Mehilli J, Frerker C, et al. Comparison of balloon-expandable vs self-expandable valves in patients undergoing transcatheter aortic valve replacement: the CHOICE randomized clinical trial. JAMA 2014;311:1503-14.

5. Gilard M, Eltchaninoff H, Iung B, et al. Registry of transcatheter aortic-valve implantation in high-risk patients. N Engl J Med 2012;366:1705-15.

6. Nuis RJ, Van Mieghem NM, Schultz CJ, et al. Frequency and causes of stroke during or after transcatheter aortic valve implantation. Am J Cardiol 2012;109:1637-43.

7. Tchetche D, Van der Boon RM, Dumonteil N, et al. Adverse impact of bleeding and transfusion on the outcome post-transcatheter aortic valve implantation: insights from the Pooled-RotterdAm-Milano-Toulouse In Collaboration Plus (PRAGMATIC Plus) initiative. Am Heart J 2012;164:402-9.

8. Borz B, Durand E, Godin M, et al. Incidence, predictors and impact of bleeding after transcatheter aortic valve implantation using the balloon-expandable Edwards prosthesis. Heart 2013;99:860-5.

9. Griese DP, Reents W, Diegeler A, et al. Simple, effective and safe vascular access site closure with the doubleProGlide preclose technique in 162 patients receiving transfemoral transcatheter aortic valve implantation. Catheter Cardiovasc Interv 2013;82:E734-41.

10. Abramowitz Y, Banai S, Katz G, et al. Comparison of early and late outcomes of TAVI alone compared to TAVI plus PCI in aortic stenosis patients with and without coronary artery disease. Catheter Cardiovasc Interv 2014;83:649-54.

11. Rodés-Cabau J, Masson JB, Welsh RC, et al. Aspirin Versus Aspirin Plus Clopidogrel as Antithrombotic Treatment Following Transcatheter Aortic Valve Replacement With a Balloon-Expandable Valve: The ARTE (Aspirin Versus Aspirin + Clopidogrel Following Transcatheter Aortic Valve Implantation) Randomized Clinical Trial. JACC Cardiovasc Interv 2017;10:1357-65.

12. Stabile E, Pucciarelli A, Cota L, et al. SAT-TAVI (single antiplatelet therapy for TAVI) study: a pilot randomized study comparing double to single antiplatelet therapy for transcatheter aortic valve implantation. Int J Cardiol 2014;174:624-7.

13. Ussia GP, Scarabelli M, Mulè M, et al. Dual antiplatelet therapy versus aspirin alone in patients undergoing transcatheter aortic valve implantation. Am J Cardiol
2011;108:1772-6.

14. Durand E, Blanchard D, Chassaing S, et al. Comparison of two antiplatelet therapy strategies in patients undergoing transcatheter aortic valve implantation. Am J Cardiol 2014;113:355-60.

15. Poliacikova P, Cockburn J, de Belder A, et al. Antiplatelet and antithrombotic treatment after transcatheter aortic valve implantation - comparison of regimes. J Invasive Cardiol 2013;25:544-8.

16. Hassell ME, Hildick-Smith D, Durand E, et al. Antiplatelet therapy following transcatheter aortic valve implantation. Heart 2015;101:1118-25.

17. Gandhi S, Schwalm JD, Velianou JL, et al. Comparison of Dual-antiplatelet Therapy to Mono-antiplatelet Therapy After Transcatheter Aortic Valve Implantation: Systematic Review and Meta-analysis. Can J Cardiol 2015;31:775-84.

18. Miyazaki Y, Suwannasom P, Sotomi Y, et al. Single or dual antiplatelet therapy after PCI. Nat Rev Cardiol 2017;14:294-303.

19. Généreux P, Giustino G, Witzenbichler B, et al. Incidence, predictors, and impact of post discharge bleeding after percutaneous coronary intervention. J Am Coll Cardiol 2015;66:1036-45.

20. Rodés-Cabau J, Dauerman HL, Cohen MG, et al. Antithrombotic treatment in transcatheter aortic valve implantation: insights for cerebrovascular and bleeding events. J Am Coll Cardiol 2013;62:2349-59.

21. Généreux P, Cohen DJ, Williams MR, et al. Bleeding complications after surgical aortic valve replacement compared with transcatheter aortic valve replacement: insights from the PARTNER I Trial (Placement of Aortic Transcatheter Valve). J Am Coll Cardiol 2014;63:1100-9.

22. Redfors B, Watson BM, McAndrew T, et al. Mortality, length of stay, and cost implications of procedural bleeding after percutaneous interventions using large-bore catheters. JAMA Cardiol 2017;2:798-802.

23. Hioki H, Watanabe Y, Kozuma K, et al. Pre-procedural dual antiplatelet therapy in patients undergoing transcatheter aortic valve implantation increases risk of bleeding. Heart 2017;103:361-7.

24. Ichibori Y, Mizote I, Maeda K, et al. Clinical Outcomes and Bioprosthetic Valve Function After Transcatheter Aortic Valve Implantation Under Dual Antiplatelet Therapy vs. Aspirin Alone. Circ J 2017;81:397-404.

25. Czerwińska-Jelonkiewicz K, Zembala M, Dąbrowski M, et al. Can TAVI patients receive aspirin monotherapy as patients after surgical aortic bioprosthesis implantation? 
Data from the Polish Registry-POL-TAVI. Int J Cardiol 2017;227:305-11.

26. Mangieri A, Jabbour RJ, Montalto C, et al. Single-

Cite this article as: Koniari I, Kounis NG, Hahalis G. Antithrombotic treatment following transcatheter valve replacement: current considerations. J Thorac Dis 2017;9(11):4251-4259. doi: 10.21037/jtd.2017.10.34 antiplatelet therapy in patients with contraindication to dual-antiplatelet therapy after transcatheter aortic valve implantation. Am J Cardiol 2017;119:1088-93. 